\title{
Stock market integration in Africa
}

\author{
Sam Agyei-Ampomah, School of Management, University of Surrey, Guildford, \\ Surrey, GU2 7XH, United Kingdom. \\ Email: s.agyei-ampomah@surrey.ac.uk
}

\begin{abstract}
Purpose: The purpose of this paper is to examine the nature and extent of linkages between African stock markets and the relationships between these markets and that of regional and global indices.
\end{abstract}

Design/methodology/approach: We analyse the monthly returns of S\&P/IFC return indices for 10 African countries over the period 1998 - 2007. The index return volatility is decomposed into three components following Barari (2004) and estimate the contribution of regional and global market movements to the local index volatility.

Findings: We find that African stock markets are still segmented from global markets in spite of recent structural adjustments and that the local index volatility is largely country-specific which can be diversified away by cross-country diversification.

Originality/value: This paper provides further evidence on stock market integration in emerging markets. The finding suggests that African stock markets, with the exception of South Africa, are still segmented from global markets. Thus, recent structural adjustment and liberalisation policies have not reduced stock market segmentation in Africa. This paper therefore has implications for policy makers and international investors.

Keywords: Equity market integration, financial liberalisation, emerging markets, Africa Paper type: Research paper 


\section{Introduction}

The issue of equity market integration has generated a lot of interest among investors, researchers and policy makers in recent times. Equity market integration and interdependencies have implications for international investors and fund managers because the degree of market integration affects the benefits of international diversification. Greater stock market integration is also of interest to policy makers in the sense that events in one market can have significant effects in other markets, as each stock market becomes an integral part of a single global market. For example, international investment inflows and outflows can have a significant influence on emerging market economies and their stock markets. Increased integration could therefore have macroeconomic and monetary policy implications, because monetary policies in a domestic economy could be affected by the linkages between the local capital market and other markets within the sub-region and globally.

This paper examines the extent to which African stock markets are influenced by external markets by analysing the degree to which Regional and Global market indices explain the behaviour of local market indices in Africa. A number of studies on the spill over effect in international stock markets suggest that international stock markets are highly correlated and interdependent. These include Hamao et al (1990), King and Wadhani (1990), Susmel and Engle (1994), Bekaert and Harvey (1997), Masih and Masih (2001) and Bekaert, Harvey and Lumsdaine (2002) among others. However, most of these studies either concentrate on the developed stock markets and where emerging markets are considered they usually exclude many of the emerging African stock markets. In the past, it has also been argued that emerging markets are segmented from world capital markets because their returns are more 
likely to be influenced by local rather than global information variables (see Harvey (1995)). However, many emerging markets, including countries in our sample, have undertaken substantial financial and economic reforms towards liberalisation in recent times, which, all things being equal should result in greater integration among themselves, as well as global markets. In theory, financial liberalisation is said to encourage integration as barriers that inhibit financial flows between markets are removed. Bekaert, Harvey and Lumsdaine (2002) thus report that emerging markets became more integrated after their liberalisation.

In spite of the recent interest in research on emerging markets, not much has been done on African stock markets. The few studies are largely concentrated on return predictabilities and efficiency of these markets. These include Graham and Smith (2006), Jefferis and Smith (2005), Appiah-Kusi and Menya (2003), Magnusson and Wydick (2002), Smith, Jefferis and Ryoo (2002) and Dickinson and Muragu (1994). All these studies confirm short term return predictabilities and violations of weak form market efficiency. Collins and Biekpe (2003) also use changes in correlations following the Asian crisis in 1997 to examine the interdependencies of African markets. They find that interdependencies in African stock markets fall into regional blocks and that, with the exception of South Africa and Egypt, the evidence does not support integration with global emerging markets. On the other hand, Wang et al (2003) find African stock markets to have time varying integration which appears to have declined after the 1997/98 crisis.

It is of interest to note that earlier studies including those reported above employ time series analysis such as cointegration analysis, vector autoregressions (VARs) as in King and Wadhani (1990) and Masih and Masih (2001) or ARCH-based models as in Susmel and Engel (1994) and Bekaert and Harvey (1997). This paper employs an alternative approach 
following Barari (2004) to examine the interlinkages among African stock markets. We decompose the volatility of the domestic index into three components; the contribution of the regional index, the contribution of the global and the unsystematic component. We then examine the regional and global integration scores over time by analysing the various components over different time periods. By this approach we are also able to quantify the contribution of regional and global market movements to the local index volatility.

Although this paper examines similar issues as in Collins and Biekpe (2003) and Wang et al (2003) our approach is different. Whilst the earlier studies examine integration with particular reference to the 1997/98 Asian crisis, our approach seeks to establish the extent to which regional and global market indices affect domestic stock market volatility in Africa. Our second objective is to examine whether the degree of integration has improved following the various structural adjustments. Although African markets may not be significant on the global stage, our paper nevertheless addresses a gap in the extant literature by providing further evidence on financial market integration. We provide a more recent and comprehensive evidence on the extent to which domestic stock market volatility is driven by global and regional shocks which to best of our knowledge has not been reported in any of the previous studies on African markets. We are also able to assess whether recent liberalisation attempts have enhanced integration in these markets.

The main results of the paper can be summarised as follows. We find that stock markets in Africa, with the exception of South Africa, are still segmented from the global market in spite of their liberalisation efforts. Also, a large part of the total volatility of the local indices comes from country-specific factors. This is an interesting phenomenon since in an integrated capital market country-specific risk which can be diversified away should not be priced. Another 
interesting aspect of our findings is the low (sometimes negative) correlation between the stock markets of countries even in the same regional economic blocs. Consistent with Wang et al (2003), we also find evidence of time varying integration and that the levels of integration with global and regional markets seem to decline over time. This appears contrary to the findings of Bekaert, Harvey and Lumsdaine (2002) that emerging markets become more integrated after their liberalisation. On a positive note, the low levels of integration therefore offer greater opportunities for risk diversification across countries.

The rest of the paper is structured as follows. In Section 2, we discuss the data and the methodology employed in the study. Section 3 discusses the empirical findings and Section 4 concludes.

\section{Data and Methodology}

The data used in the analysis include monthly total returns in both local currency and US dollars for the S\&P/IFC indices for 10 African countries. Four of these are in the IFC (Global) category (Egypt, Morocco, Nigeria and South Africa) and the other six in the IFC (Frontier) category (Botswana, Ivory Coast, Ghana, Kenya, Mauritius and Tunisia). Both local and the equivalent dollar returns in these markets were used in the analysis with more emphasis on the dollar denominated monthly total returns. There are at least 20 stock exchanges in Africa but not all of them are covered in the S\&P/IFC database and although most of the markets have been in existence earlier than 1997, the S\&P/IFC domestic indices data are not available before 1997. Although Namibia and Zimbabwe are covered in the IFC Indices, they have been excluded from our analysis due to data considerations. Data on Namibia is only 
available from 2000, and data on Zimbabwe were highly volatile due to the political and economic situation in the country.

The sample period is from January 1998 to December 2007, a total of 120 monthly observations. As these markets are thinly traded, we focus on monthly returns as this addresses many of the microstructural biases such as nonsynchronous trading and stale pricing. The S\&P Global 1200 Index is used as a proxy for the global benchmark and for the regional benchmark, we use the S\&P/IFCG Middle East \& Africa Index ${ }^{1}$. All the return indices were extracted from Datastream.

\subsection{Measuring regional and global integration scores}

To assess the degree of integration with regional and global markets, we follow the methodology of Barari (2004). This section therefore draws heavily on Barari (2004). Let $\mathrm{R}_{\mathrm{i}}$ denote the rate of return on the ith country index, $R_{r}$ denote the rate of return on the regional benchmark index and $\mathrm{R}_{\mathrm{g}}$ be the rate of return on the global benchmark index. Assume that the return of the domestic index follows a two-index return-generating process given by:

$$
\mathrm{R}_{\mathrm{i}}=\alpha_{\mathrm{i}}+\beta_{\mathrm{ir}} U_{\mathrm{r}}+\beta_{\mathrm{ig}} R_{\mathrm{g}}+\varepsilon_{\mathrm{i}}
$$

where $U_{\mathrm{r}}$, is obtained as the residual from the following regression

$$
\mathrm{R}_{\mathrm{r}}=\lambda+\beta_{\mathrm{r}} R_{\mathrm{g}}+U_{\mathrm{r}}
$$

and $\varepsilon_{\mathrm{i}}$ is the country-specific residual error term. The sample countries have all gone through significant adjustments to formally make their financial markets accessible to the outside world. From an international finance perspective, financial liberalisation will lead to

\footnotetext{
${ }^{1}$ In another analysis we used the FTSE World Return Index as the global benchmark but the results were identical. The correlation between the FTSE World index and the S\&P Global 1200 Index were 94.0\% and 99.8\% during the January 1998 - December 2007 and January 2003 - December 2007 periods, respectively.
} 
equalisation of price factors. However, because country specific circumstances can lead to different levels of systematic risk, the coefficients $\alpha_{i}, \beta_{\text {ir }}$ and $\beta_{\text {ig }}$ are country-specific. For example, in spite of financial liberalisation, factor immobility in resource-endowed countries can lead to differences in returns ${ }^{2}$. The residual error term, $\varepsilon_{\mathrm{i}}$, is assumed to be random, nonautocorrelated with mean zero and orthogonal to $U_{\mathrm{r}}$ and $R_{\mathrm{g}}$. As both the global and regional indices may be driven by common factors, equation (2) ensures that any common trends are removed. Thus $U_{\mathrm{r}}$ is orthogonal to the global returns, $R_{\mathrm{g}}$ and represents that part of the variation in $R_{\mathrm{r}}$ that cannot be explained by $R_{\mathrm{g}}$.

As $\varepsilon_{\mathrm{i}}$ is also orthogonal to both $\mathrm{R}_{\mathrm{g}}$ and $U_{\mathrm{r}}$, the variance of the local index return can be expressed as the sum of three components:

$$
\operatorname{Var}\left(\mathrm{R}_{\mathrm{i}}\right)=\left(\beta_{\mathrm{ir}}\right)^{2} \operatorname{Var}\left(\mathrm{U}_{\mathrm{r}}\right)+\left(\beta_{\mathrm{ig}}\right)^{2} \operatorname{Var}\left(\mathrm{R}_{\mathrm{g}}\right)+\operatorname{Var}\left(\varepsilon_{\mathrm{i}}\right)
$$

Dividing both sides by $\operatorname{Var}\left(\mathrm{R}_{\mathrm{i}}\right)$, we have

$$
a_{\mathrm{i}}+b_{\mathrm{i}}+c_{\mathrm{i}}=1
$$

where,

$$
\begin{aligned}
& a_{\mathrm{i}}=\left(\beta_{\mathrm{ir}}\right)^{2} \operatorname{Var}\left(\mathrm{U}_{\mathrm{r}}\right) / \operatorname{Var}\left(\mathrm{R}_{\mathrm{i}}\right) \\
& \mathrm{b}_{\mathrm{i}}=\left(\beta_{\mathrm{ig}}\right)^{2} \operatorname{Var}\left(\mathrm{R}_{\mathrm{g}}\right) / \operatorname{Var}\left(\mathrm{R}_{\mathrm{i}}\right) \\
& \mathrm{c}_{\mathrm{i}}=\operatorname{Var}\left(\varepsilon_{\mathrm{i}}\right) / \operatorname{Var}\left(\mathrm{R}_{\mathrm{i}}\right)
\end{aligned}
$$

Thus, $a_{\mathrm{i}}$ measures the proportion of the total domestic variance explained by the regional index (that is uncorrelated with global systematic risk), $b_{\mathrm{i}}$ measures the proportion explained by the global systematic risk and $c_{\mathrm{i}}$ measures the component of country-specific risk. We

\footnotetext{
${ }^{2}$ From an international finance framework, if markets were fully integrated we would expect common pricing effects so that $\beta_{\mathrm{i}}=\beta, \forall \mathrm{i}$. This also implies that expected return should be identical across countries but this need not be the case if some country specific factors are systematic.
} 
therefore use as $a_{\mathrm{i}}$ and $b_{\mathrm{i}}$ as measures of country i's regional and global integration, respectively. Higher levels of $a_{\mathrm{i}}$ and $b_{\mathrm{i}}$ would be interpreted as evidence of greater integration.

\section{Empirical Findings}

\subsection{Descriptive Statistics}

Figure 1 shows the monthly index levels of the IFC country indices with January 1998 set to 100. Panel A presents the indices in local currency terms whilst Panel B presents the dollar equivalents. Figure 1 shows that most of the indices had only moderate appreciation between 1998 and December 2002. ${ }^{3}$ The best performing market over the period is Botswana although it witnessed a sharp decline, in dollar terms, in May 2005, with Ghana being the worst performing market when the returns are converted into the dollars. This reflects the continuous depreciation of the local currency relative to the US dollar and emphasises the importance of currency risk in international equity returns.

Table 1 reports descriptive statistics for the corresponding country indices and the regional and global indices. For comparison purposes all returns are calculated from the US dollar equivalents of the various indices. The mean monthly returns, over the entire sample period, ranges from $0.22 \%$ in Ghana to $2.43 \%$ in Botswana. Over the entire period, all the country indices exhibit considerable non-normality, characterised by very high kurtosis and skewness measures. The Jarque Bera test of normality is rejected at the $5 \%$ level of significance for all the indices including the regional and global benchmarks. This phenomenon is however not

\footnotetext{
${ }^{3}$ The sample period is just split into two equal halves (5-year periods) to assess whether the characteristics of the sample in both periods are the same.
} 
stable as the two sub-periods exhibit different levels of non-normality. Panels B and C also show that the return characteristics of the various indices differ in the two sub-periods. For example, whilst Egypt was the worst performing market in the first sub-period ((January 1998 - December 2002), it is the best performing market in the second subperiod (January 2003 December 2007). The results thus indicate time-varying returns in these stock markets.

\subsection{Correlation tests}

Table 2 presents the monthly return correlations between the markets. Given the nonnormality of the data (as shown in Table 1), we present both the Pearson product moment correlation coefficients and the nonparametric Spearman rank correlations. In each panel, cells above the diagonal (top right corner of the table) report the Spearman rank correlation coefficients whilst cells below the diagonal (bottom left corner of the table) report the corresponding Pearson correlation coefficients. As shown, the magnitudes of the correlation coefficients are largely similar in both cases but a few sign changes. For example, Panel A presents the correlation matrix for the full sample period, whilst Panels B and C present the correlations for the two sub periods. The results show that the markets have generally low correlations both among themselves and with the regional and world indices. For example, of the 45 pair-wise correlations (Pearson's) among the country indices in Panel A, 20 of these are either negative or less than $10 \%$. We find similar evidence of either negative or very low correlations in the majority of cases in both the first and second sub-periods. On the whole, South Africa has the highest correlation coefficient with both the regional index and the global index. Its high correlation with the regional index is not surprising as South Africa accounts for a very significant share in the regional index. In the second sub-period Morocco and Botswana also show higher levels of correlation with the Regional and the Global indices. 
Accordingly, we would expect these markets to be more integrated with the Regional and Global market than the others. On the whole the results show that these markets are still much segmented.

The highest correlations between the countries occur between Botswana and South Africa, Egypt and South Africa and Mauritius and Kenya. South Africa and Egypt are among the oldest and most developed exchanges. The higher correlations between Botswana and South Africa and Kenya and Mauritius could also be explained by the industrial composition of their country indices. Mauritius and Kenya are likely to be dominated by the hospitality sector whilst the mining sector dominates the indices in South Africa and Botswana. Thus the driving factor here might be more of industry related factors than the extent of economic activities between the countries. Contrary to Biekpe and Collins (2003), we do not find evidence to suggest that interdependencies in African markets fall into regional blocs. For example, the correlation between the three markets in the ECOWAS bloc, Ivory Coast, Ghana and Nigeria, show a very low or negative correlation over the entire sample period. This is particularly interesting because these regional blocs are expected to facilitate greater political and economic links between countries. Our results is also contrary to Yang et al (2006) who also find evidence of regional correlation clusters in a study of 8 industrialised countries.

On the average, correlations increased in the second sub-period, both within the markets and with the regional and world markets, and might suggest increasing levels of financial integration between these countries. It should however be noted that the effectiveness of correlation analysis in examining linkages between markets might be limited because of the possibility of spurious correlation. An increase in correlation might not necessarily mean an 
increase in financial integration as both countries might be correlated to a common factor (e.g. the global market) but not between themselves.

\subsection{Integration Scores}

In this section we estimate the proportion of the local index variability that is explained by the regional and global indices. To take into account possible time-variation in these values, we use two windowing strategies. In Table 3 we present the estimation results using an expanding window. We begin with the first 4-year data from January 1998 to December 2001 and increase the window in 12-month intervals. Thus, the first sub-period covers January 1998 - December 2001, the second sub-period covers January 1998 - December 2002 and so on until the full sample is used. Table 4 on the other hand presents the estimation results using a fixed 4-year rolling window which is moved forward in 12-month intervals. In this case the first sub-period is January 1998 - December 2001, the second covers the period January 1999 - December 2002 and so on yielding seven 4-year windows. In this case, the estimation uses the most recent data in the period and thus reduces the influence of extreme historical variations on the integration scores.

The results in Tables 3 and 4 show that these markets have very low levels of regional and global integration scores, except South Africa; yet in all countries the regional integration score exceeds the global score. In most cases, the proportion of the total domestic variance explained by the regional and global indices collectively is less than 15\%. Ghana, Kenya, Mauritius and Tunisia exhibit the lowest global integration scores over the period, irrespective of the method of estimation. Our results show that with the exception of South Africa, the markets in Africa carry a lot of country-specific risks. Indeed, the results confirm that the 
nature of the South African market is completely different from that of the other countries in Africa. The global and regional integration scores of South Africa are also comparable to those of the Latin America countries reported in Barari (2004).

We acknowledge that the effect of liberalisation may not be instantaneous. However, if the liberalisation processes in these countries were effective, we should expect to see gradual improvements in integration over time. We also find that although South Africa shows evidence of increasing global integration as the estimation window expands (Table 3), we find evidence of declining levels of global integration using the fixed 4-year windows (Table 4). This is consistent with the findings of Wang et al (2003). In a study of some of these markets they report evidence of time varying integration which seem to have declined after the 1997/98 emerging market crisis. In Figure 2, we present a graph of the sum of the regional and global integration scores from the rolling window estimation. The graph offers a clear comparison of the degree of integration across the countries and over time. The dominance of the South African market is clearly evident in Figure 2. Clearly, both regional and global stock market variations jointly explain a very small part of the local market volatility.

On the whole, our results suggest that there is a great deal of potential for cross country diversification in these markets, as a large part of the total domestic variance appears countryspecific. Our results also show that the liberalisation attempts in Africa have not yet achieved the desired financial integration with the global financial markets. African stock markets are, to a large extent, still segmented. It is therefore not surprising that the earlier studies found that the Asian crisis had no effect on African markets. 


\section{Conclusion}

In this paper we examine whether the major stock markets in Africa have become more integrated into the global capital market. We present some new results that examine the levels of regional and global integration in these markets. We find that the low levels of correlation among African markets themselves and also with the regional and global market reported in previous studies still persist. Apart from South Africa, we do not find any evidence that African markets are integrated with the global stock market. Using a two-index return generating function, our results also show that the total volatility of the domestic index in these markets is largely country-specific. The proportion of the total volatility attributed to the residual term substantially dominates the proportion attributed to the regional and global indices.

We also find that though these markets experience time-varying integration, the level of integration has diminished over time. Thus, these markets have become even more segmented in recent times. In spite of the development of sub-regional blocs, African markets are still far from being integrated even on a regional basis. If the economies of countries in the regional blocs are related in anyway at all, this is not reflected in the behaviour of their stock markets. There are therefore stronger diversification benefits in these markets for fund managers within and out of Africa, if perceptions of African stock markets would change. Although, significant costs and constraints (political and economic) still persists in these markets, significant reforms are still being pursued to enhance transparency in market transactions and liquidity. It is important for investors and fund managers in Africa to take advantage of these benefits and invest beyond their domestic markets. 


\section{References}

Appiah-Kusi, J. and Menyah K. (2003), “Returns predictability in African stock markets”, Review of Financial Economics, Vol. 12, pp. $247-70$.

Barari, M. (2004), “Equity market integration in Latin America: A time varying integration score analysis”, International Review of Financial Analysis, Vol. 13, pp. 649-68.

Bekaert, G. and Harvey, C.R. (2000), “Foreign speculators and emerging equity markets”, Journal of Finance, Vol. 55, pp. 565-614.

Bekaert G., Erb, C.B., Harvey, C.R. and Viskanta, T.E. (1998), “Distributional characteristics of emerging market returns and asset allocation”, Journal of Portfolio Management, Vol. 24, pp. 102-16.

Bekaert G. and Harvey, C.R. (2003), “Emerging markets finance”, Journal of Empirical Finance, Vol. 10, pp. 3-55.

Bekaert, G., Harvey, C.R. and Lumsdaine, R. (2002), “Dating the integration of world equity markets”, Journal of Financial Economics, Vol. 65, pp. 203-49.

Bekaert G. and Harvey, C.R. (1997), “Emerging equity market volatility”, Journal of Financial Economics, Vol. 43, pp. 29-77.

Bekaert, G. and Harvey, C.R. (1995), “Time-varying world market integration”, Journal of Finance, Vol. 50, pp. 403-44.

Collins, D. and Biekpe, N. (2003), “Contagion and interdependence in African stock markets”, South African Journal of Economics, Vol. 71, pp. 181-95.

Dickinson, J. P. and Muragu, K. (1994), “Market efficiency in developing countries: A case study of the Nairobi stock exchange”, Journal of Business Finance and Accounting, Vol. 21, pp. 133-49.

Hamao, Y., Masulis, R. and Ng, V. (1990), “Correlations in price changes and volatility across international stock markets”, Review of Financial Studies, Vol. 3, pp. 281-307. 
Harvey, C.R. (1995), “Predictable risk and returns in emerging markets”, Review of Financial Studies, Vol. 8, pp. 773-816.

Jefferis, K. and Smith, G. (2005), “The changing efficiency of African stock markets”, The South African Journal of Economics, Vol. 73, pp. 54-67.

King, M. A., and Wadhwani, S. (1990), “Transmission of volatility between stock markets”, Review of Financial Studies, Vol. 3, pp. 5-33.

Magnusson, M. A. and Wydick, B. (2002), “How efficient are Africa’s emerging stock markets?”, The Journal of Development Studies, Vol. 38, pp. 141-56.

Masih, R. and Masih, A. M. M. (2001), “Long and short term dynamic causal transmission amongst international stock markets”, Journal of International Money and Finance, Vol. 20, pp. 563-87.

Smith, G., Jefferis, K. and Ryoo, H-J. (2002), “African stock markets: multiple variance ratio tests of random walks”, Applied Financial Economics, Vol. 12, pp. 475-84.

Susmel, R. and Engle, R. F.(1994), “Hourly volatility spillover between international equity markets”, Journal of International Money and Finance, Vol. 13, pp. 3-25.

Wang, Z., Yang, D. and Bessler, A. (2003), “Financial crisis and African stock market integration”, Applied Economics Letters, Vol. 10, pp. 527-33.

Yang, L., Tapon, F. and Sun, Y. (2006), “International correlations across stock markets and industries: trends and patterns 1988 - 2002”, Applied Financial Economics, Vol. 16, pp. 1171-83. 
Table 1: Country, Regional and Global Index Monthly Returns - Descriptive Statistics

Table 1 reports descriptive statistics for the country indices and the regional and global indices. All returns are calculated from the US dollar equivalents of the various indices and cover the period January 1998 to December 2007. Panel A presents results for the full sample period whilst Panels B and C present results for the two sub-periods, January 1998 to December 2002 and January 2003 to December 2007, respectively.

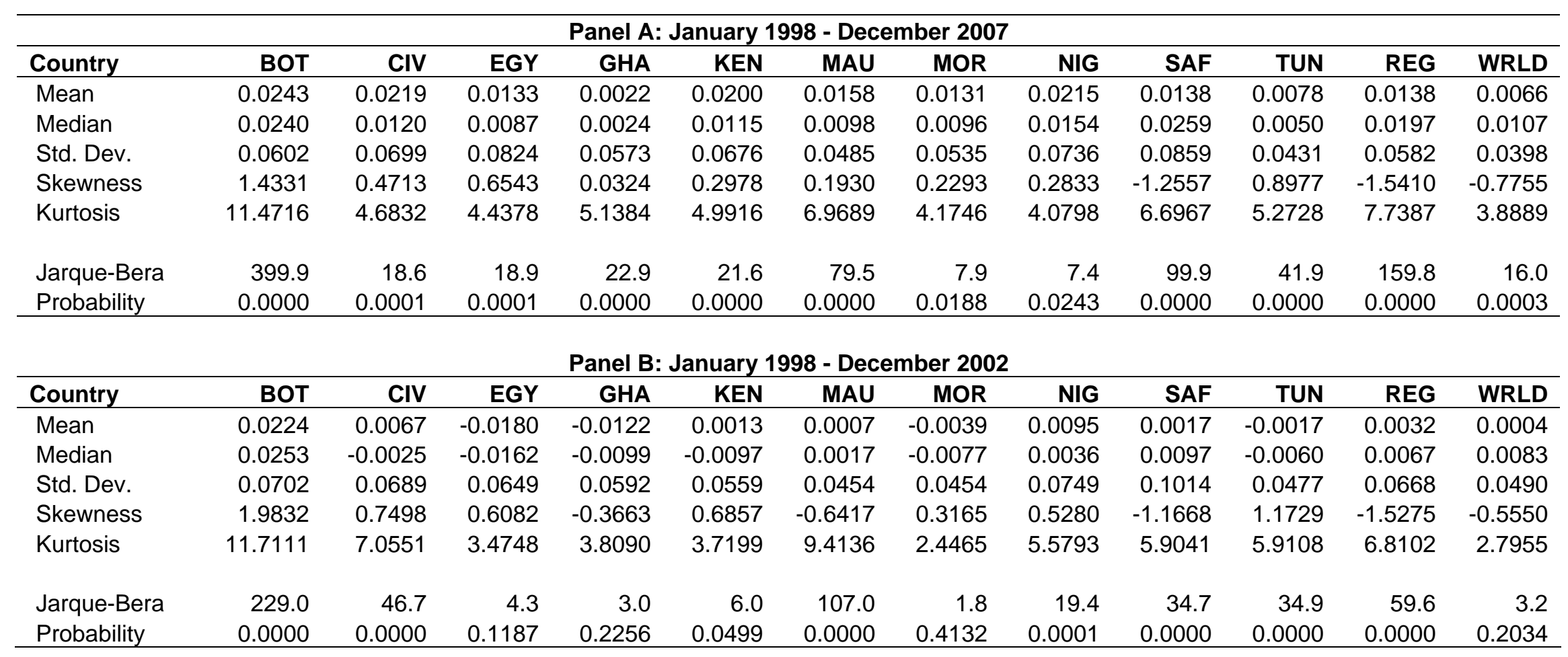


Table 1: Country, Regional and Global Index Monthly Returns - Descriptive Statistics(cont'd)

\begin{tabular}{|c|c|c|c|c|c|c|c|c|c|c|c|c|}
\hline \multirow[b]{2}{*}{ Country } & \multicolumn{9}{|c|}{ Panel C: January 2003 - December 2007} & \multirow[b]{2}{*}{ TUN } & \multirow[b]{2}{*}{ REG } & \multirow[b]{2}{*}{ WRLD } \\
\hline & BOT & CIV & EGY & GHA & KEN & MAU & MOR & NIG & SAF & & & \\
\hline Mean & 0.0261 & 0.0371 & 0.0445 & 0.0165 & 0.0386 & 0.0309 & 0.0301 & 0.0336 & 0.0259 & 0.0173 & 0.0244 & 0.0129 \\
\hline Median & 0.0239 & 0.0325 & 0.0395 & 0.0082 & 0.0293 & 0.0258 & 0.0304 & 0.0341 & 0.0399 & 0.0106 & 0.0289 & 0.0139 \\
\hline Std. Dev. & 0.0487 & 0.0682 & 0.0866 & 0.0518 & 0.0734 & 0.0471 & 0.0558 & 0.0708 & 0.0657 & 0.0359 & 0.0462 & 0.0267 \\
\hline Skewness & -0.3436 & 0.2707 & 0.4058 & 0.8890 & -0.1548 & 0.9411 & -0.0735 & 0.0800 & -0.6330 & 1.0110 & -0.8544 & -0.0891 \\
\hline Kurtosis & 4.7547 & 3.0272 & 4.8062 & 6.3788 & 5.9006 & 4.5980 & 5.4178 & 2.6887 & 2.9652 & 4.5327 & 5.3053 & 2.6828 \\
\hline Jarque-Bera & 8.9 & 0.7 & 9.8 & 36.4 & 21.3 & 15.2 & 14.7 & 0.3 & 4.0 & 16.1 & 20.6 & 0.3 \\
\hline Probability & 0.0118 & 0.6926 & 0.0074 & 0.0000 & 0.0000 & 0.0005 & 0.0007 & 0.8580 & 0.1347 & 0.0003 & 0.0000 & 0.8475 \\
\hline
\end{tabular}


Table 2 presents the monthly return correlations between the markets. We present both the Pearson product moment correlation coefficients and the nonparametric Spearman rank correlations. In each panel, cells above the diagonal (top right corner of the table) report the Spearman rank correlation coefficients whilst cells below the diagonal (bottom left corner of the table) report the corresponding Pearson correlation coefficients. All returns are calculated from the US dollar equivalents of the various indices and cover the period January 1998 to December 2007 . Panel A presents results for the full sample period whilst Panels B and C present results for the two sub-periods, January 1998 to December 2002 and January 2003 to December 2007, respectively.

Panel A: January 1998 - December 2007

\begin{tabular}{lrrrrrrrrrrrr}
\hline Country & BOT & CIV & EGY & GHA & KEN & MAU & MOR & NIG & SAF & TUN & REG & WRLD \\
\hline BOT & 1 & 0.081 & 0.072 & 0.125 & -0.016 & 0.131 & 0.196 & 0.114 & 0.446 & 0.096 & 0.300 & 0.085 \\
CIV & 0.025 & 1 & 0.224 & 0.076 & 0.026 & 0.152 & 0.285 & 0.068 & 0.160 & 0.329 & 0.223 & -0.044 \\
EGY & 0.004 & 0.165 & 1 & 0.074 & 0.145 & 0.350 & 0.145 & 0.122 & 0.336 & 0.155 & 0.430 & 0.167 \\
GHA & 0.140 & 0.074 & 0.032 & 1 & 0.127 & 0.113 & 0.243 & -0.092 & -0.019 & 0.109 & -0.104 & 0.069 \\
KEN & -0.106 & 0.033 & 0.117 & 0.115 & 1 & 0.306 & 0.160 & 0.052 & 0.010 & 0.047 & -0.007 & 0.048 \\
MAU & 0.044 & 0.065 & 0.196 & 0.129 & 0.276 & 1 & 0.217 & 0.232 & 0.134 & 0.126 & 0.136 & 0.095 \\
kdf & 0.184 & 0.301 & 0.146 & 0.203 & 0.111 & 0.13 & 1 & 0.059 & 0.252 & 0.226 & 0.239 & 0.026 \\
NIG & 0.069 & 0.103 & 0.037 & -0.113 & 0.022 & 0.216 & 0.071 & 1 & 0.095 & -0.053 & 0.188 & -0.054 \\
SAF & 0.347 & 0.144 & 0.333 & -0.021 & -0.009 & 0.081 & 0.202 & 0.147 & 1 & 0.097 & 0.779 & 0.220 \\
TUN & 0.201 & 0.237 & 0.120 & 0.003 & 0.061 & 0.071 & 0.227 & 0.003 & 0.118 & 1 & 0.027 & 0.095 \\
REG & 0.249 & 0.183 & 0.411 & -0.068 & -0.005 & 0.094 & 0.168 & 0.187 & 0.861 & 0.072 & 1 & 0.112 \\
WRLD & 0.119 & -0.061 & 0.268 & -0.067 & 0.106 & 0.085 & 0.178 & 0.111 & 0.508 & 0.005 & 0.495 & 1 \\
\hline
\end{tabular}


Table 2: Monthly return correlations (cont'd)

Panel B: January 1998 - December 2002

\begin{tabular}{lrrrrrrrrrrrr}
\hline Country & BOT & CIV & EGY & GHA & KEN & MAU & MOR & NIG & SAF & TUN & REG & WRLD \\
\hline BOT & 1 & 0.040 & -0.093 & 0.212 & 0.019 & 0.036 & 0.203 & 0.130 & 0.406 & 0.065 & 0.408 & -0.116 \\
CIV & -0.033 & 1 & 0.180 & -0.079 & -0.111 & 0.060 & 0.229 & 0.108 & 0.179 & 0.228 & 0.193 & -0.112 \\
EGY & -0.092 & 0.192 & 1 & 0.052 & -0.071 & 0.207 & 0.063 & 0.106 & 0.392 & 0.219 & 0.377 & 0.186 \\
GHA & 0.167 & -0.195 & 0.059 & 1 & 0.068 & 0.086 & 0.111 & -0.361 & -0.019 & 0.002 & -0.027 & -0.058 \\
KEN & -0.131 & -0.130 & -0.048 & 0.031 & 1 & 0.220 & -0.067 & 0.006 & -0.004 & -0.171 & -0.036 & -0.017 \\
MAU & -0.031 & -0.091 & 0.021 & 0.063 & 0.187 & 1 & 0.071 & 0.070 & 0.082 & 0.042 & 0.098 & -0.013 \\
MOR & 0.259 & 0.187 & 0.012 & 0.206 & -0.105 & 0.003 & 1 & -0.091 & 0.164 & 0.162 & 0.190 & -0.108 \\
NIG & 0.075 & 0.149 & 0.027 & -0.305 & -0.062 & 0.095 & -0.051 & 1 & 0.293 & -0.134 & 0.326 & 0.004 \\
SAF & 0.301 & 0.114 & 0.392 & -0.074 & -0.060 & 0.016 & 0.028 & 0.290 & 1 & 0.064 & 0.948 & 0.207 \\
TUN & 0.208 & 0.208 & 0.158 & -0.070 & -0.185 & -0.005 & 0.087 & -0.046 & 0.070 & 1 & 0.012 & -0.052 \\
REG & 0.305 & 0.121 & 0.413 & -0.078 & -0.046 & 0.052 & 0.041 & 0.271 & 0.961 & 0.057 & 1 & 0.187 \\
WRLD & 0.088 & -0.192 & 0.314 & -0.058 & 0.057 & 0.019 & -0.002 & 0.142 & 0.496 & -0.137 & 0.531 & 1 \\
\hline
\end{tabular}

Panel C: January 2003 - December 2007

\begin{tabular}{lrrrrrrrrrrrr}
\hline Country & BOT & CIV & EGY & GHA & KEN & MAU & MOR & NIG & SAF & TUN & REG & WRLD \\
\hline BOT & 1 & 0.054 & 0.189 & 0.072 & -0.060 & 0.188 & 0.091 & 0.034 & 0.503 & 0.105 & 0.178 & 0.290 \\
CIV & 0.095 & 1 & 0.062 & 0.031 & 0.022 & 0.059 & 0.223 & -0.089 & 0.019 & 0.269 & 0.116 & -0.044 \\
EGY & 0.081 & 0.016 & 1 & -0.192 & 0.107 & 0.278 & -0.016 & 0.016 & 0.277 & -0.062 & 0.431 & 0.012 \\
GHA & 0.089 & 0.268 & -0.186 & 1 & 0.064 & -0.015 & 0.114 & 0.022 & -0.036 & 0.031 & -0.290 & 0.132 \\
KEN & -0.119 & 0.048 & 0.047 & 0.066 & 1 & 0.259 & 0.256 & -0.021 & 0.029 & 0.169 & -0.002 & -0.027 \\
MAU & 0.132 & 0.082 & 0.137 & 0.046 & 0.225 & 1 & 0.142 & 0.305 & 0.146 & 0.055 & 0.054 & 0.078 \\
MOR & 0.114 & 0.306 & 0.038 & 0.071 & 0.104 & 0.058 & 1 & 0.053 & 0.264 & 0.200 & 0.146 & 0.059 \\
NIG & 0.052 & -0.014 & -0.074 & 0.011 & 0.005 & 0.259 & 0.081 & 1 & -0.175 & -0.113 & -0.050 & -0.161 \\
SAF & 0.448 & 0.128 & 0.246 & -0.036 & -0.048 & 0.076 & 0.362 & -0.133 & 1 & 0.125 & 0.563 & 0.200 \\
TUN & 0.184 & 0.189 & -0.076 & -0.035 & 0.185 & 0.011 & 0.269 & -0.02 & 0.131 & 1 & 0.024 & 0.211 \\
REG & 0.130 & 0.197 & 0.377 & -0.191 & -0.081 & 0.024 & 0.219 & 0.000 & 0.630 & -0.013 & 1 & -0.081 \\
WRLD & 0.189 & 0.063 & 0.162 & -0.232 & 0.094 & 0.075 & 0.372 & -0.009 & 0.508 & 0.226 & 0.354 & 1
\end{tabular}


Table 3: Integration Scores - Historical

Table 3 presents the estimation results of the integration scores using an expanding window. For each country $i$ we calculate:

$$
\begin{aligned}
& a_{\mathrm{i}}=\left(\beta_{\mathrm{ir}}\right)^{2} \operatorname{Var}\left(\mathrm{U}_{\mathrm{r}}\right) / \operatorname{Var}\left(\mathrm{R}_{\mathrm{i}}\right) \\
& \mathrm{b}_{\mathrm{i}}=\left(\beta_{\mathrm{ig}}\right)^{2} \operatorname{Var}\left(\mathrm{R}_{\mathrm{g}}\right) / \operatorname{Var}\left(\mathrm{R}_{\mathrm{i}}\right) \\
& \mathrm{c}_{\mathrm{i}}=\operatorname{Var}\left(\varepsilon_{\mathrm{i}}\right) / \operatorname{Var}\left(\mathrm{R}_{\mathrm{i}}\right)
\end{aligned}
$$

where

$\mathrm{R}_{\mathrm{i}}=\alpha_{\mathrm{i}}+\beta_{\mathrm{ir}} U_{\mathrm{r}}+\beta_{\mathrm{ig}} R_{\mathrm{g}}+\varepsilon_{\mathrm{i}}$ and $U_{\mathrm{r}}$, is obtained as the residual from the regression

$$
\mathrm{R}_{\mathrm{r}}=\lambda+\beta_{\mathrm{r}} R_{\mathrm{g}}+U_{\mathrm{r}}
$$

$\mathrm{R}_{\mathrm{i}}$ denotes the return on the index of country $i$ whilst $\mathrm{R}_{\mathrm{r}}$ and $\mathrm{R}_{\mathrm{g}}$ denote the return on the regional benchmark index and the global benchmark index respectively. The S\&P Global 1200 Index is used as a proxy for the global benchmark and S\&P/IFCG Middle East \& Africa Index is used as the regional benchmark. We begin with the first 4-year

\begin{tabular}{|c|c|c|c|c|c|c|c|c|c|c|c|c|c|c|c|}
\hline \multirow{2}{*}{ PERIOD } & \multicolumn{3}{|c|}{ BOTSWANA } & \multicolumn{3}{|c|}{ IVORY COAST } & \multicolumn{3}{|c|}{ EGYPY } & \multicolumn{3}{|c|}{ GHANA } & \multicolumn{3}{|c|}{ KENYA } \\
\hline & $\mathbf{a}$ & b & C & A & b & C & $\mathbf{a}$ & b & C & $\mathbf{a}$ & b & C & $\mathbf{a}$ & b & C \\
\hline 01/98 - 12/01 & 0.099 & 0.002 & 0.899 & 0.095 & 0.049 & 0.856 & 0.063 & 0.142 & 0.796 & 0.010 & 0.001 & 0.989 & 0.024 & 0.016 & 0.960 \\
\hline $01 / 98-12 / 02$ & 0.092 & 0.008 & 0.900 & 0.069 & 0.037 & 0.894 & 0.085 & 0.099 & 0.817 & 0.003 & 0.003 & 0.994 & 0.008 & 0.003 & 0.989 \\
\hline $01 / 98-12 / 03$ & 0.090 & 0.008 & 0.902 & 0.082 & 0.029 & 0.889 & 0.077 & 0.136 & 0.787 & 0.002 & 0.004 & 0.994 & 0.001 & 0.010 & 0.989 \\
\hline $01 / 98-12 / 04$ & 0.094 & 0.007 & 0.899 & 0.072 & 0.011 & 0.916 & 0.073 & 0.110 & 0.817 & 0.002 & 0.007 & 0.991 & 0.000 & 0.015 & 0.985 \\
\hline 01/98 - 12/05 & 0.086 & 0.006 & 0.908 & 0.064 & 0.009 & 0.928 & 0.068 & 0.070 & 0.863 & 0.000 & 0.008 & 0.992 & 0.000 & 0.015 & 0.985 \\
\hline 01/98 - 12/06 & 0.058 & 0.011 & 0.931 & 0.062 & 0.003 & 0.936 & 0.091 & 0.074 & 0.835 & 0.001 & 0.007 & 0.992 & 0.001 & 0.016 & 0.982 \\
\hline $01 / 98-12 / 07$ & 0.048 & 0.014 & 0.938 & 0.060 & 0.004 & 0.936 & 0.103 & 0.072 & 0.826 & 0.002 & 0.004 & 0.994 & 0.004 & 0.011 & 0.984 \\
\hline \multirow{2}{*}{ PERIOD } & \multicolumn{3}{|c|}{ MAURITIUS } & \multicolumn{3}{|c|}{ MORROCO } & \multicolumn{3}{|c|}{ NIGERIA } & \multicolumn{3}{|c|}{ SOUTH AFRICA } & \multicolumn{3}{|c|}{ TUNISIA } \\
\hline & $\mathbf{a}$ & b & C & A & b & C & $\mathbf{a}$ & b & C & $\mathbf{a}$ & b & C & $\mathbf{a}$ & b & C \\
\hline $01 / 98-12 / 01$ & 0.000 & 0.015 & 0.985 & 0.009 & 0.006 & 0.985 & 0.066 & 0.010 & 0.924 & 0.661 & 0.291 & 0.048 & 0.018 & 0.004 & 0.978 \\
\hline $01 / 98-12 / 02$ & 0.002 & 0.000 & 0.997 & 0.002 & 0.000 & 0.998 & 0.053 & 0.020 & 0.927 & 0.678 & 0.246 & 0.076 & 0.023 & 0.019 & 0.958 \\
\hline 01/98 - 12/03 & 0.003 & 0.001 & 0.996 & 0.020 & 0.002 & 0.978 & 0.058 & 0.019 & 0.923 & 0.679 & 0.230 & 0.091 & 0.023 & 0.002 & 0.975 \\
\hline $01 / 98-12 / 04$ & 0.004 & 0.004 & 0.992 & 0.011 & 0.006 & 0.983 & 0.032 & 0.021 & 0.947 & 0.656 & 0.239 & 0.105 & 0.025 & 0.001 & 0.975 \\
\hline 01/98 - 12/05 & 0.003 & 0.006 & 0.990 & 0.010 & 0.010 & 0.980 & 0.034 & 0.017 & 0.949 & 0.588 & 0.253 & 0.160 & 0.033 & 0.001 & 0.966 \\
\hline 01/98 - 12/06 & 0.001 & 0.011 & 0.988 & 0.011 & 0.028 & 0.961 & 0.025 & 0.014 & 0.961 & 0.500 & 0.260 & 0.240 & 0.007 & 0.000 & 0.993 \\
\hline $01 / 98-12 / 07$ & 0.004 & 0.007 & 0.989 & 0.008 & 0.032 & 0.960 & 0.023 & 0.012 & 0.965 & 0.492 & 0.259 & 0.250 & 0.006 & 0.000 & 0.994 \\
\hline
\end{tabular}
data from January 1998 to December 2001 and increase the window in 12-month intervals. Thus, the first sub-period covers January 1998 - December 2001 , the second subperiod covers January 1998 - December 2002 and so on until the full sample is used. All returns are calculated from the US dollar equivalents of the various indices and the full sample period is January 1998 to December 2007. 
Table 4: Integration Scores - Rolling Windows

Table 4 presents the estimation results of the integration scores using a fixed rolling window. For each country $i$ we calculate:

$$
\begin{aligned}
& a_{\mathrm{i}}=\left(\beta_{\mathrm{ir}}\right)^{2} \operatorname{Var}\left(\mathrm{U}_{\mathrm{r}}\right) / \operatorname{Var}\left(\mathrm{R}_{\mathrm{i}}\right) \\
& \mathrm{b}_{\mathrm{i}}=\left(\beta_{\mathrm{ig}}\right)^{2} \operatorname{Var}\left(\mathrm{R}_{\mathrm{g}}\right) / \operatorname{Var}\left(\mathrm{R}_{\mathrm{i}}\right) \\
& \mathrm{c}_{\mathrm{i}}=\operatorname{Var}\left(\varepsilon_{\mathrm{i}}\right) / \operatorname{Var}\left(\mathrm{R}_{\mathrm{i}}\right)
\end{aligned}
$$

where

$$
\begin{aligned}
& \mathrm{R}_{\mathrm{i}}=\alpha_{\mathrm{i}}+\beta_{\mathrm{ir}} U_{\mathrm{r}}+\beta_{\mathrm{ig}} R_{\mathrm{g}}+\varepsilon_{\mathrm{i}} \quad \text { and } U_{\mathrm{r}} \text {, is obtained as the residual from the regression } \\
& \mathrm{R}_{\mathrm{r}}=\lambda+\beta_{\mathrm{r}} R_{\mathrm{g}}+U_{\mathrm{r}}
\end{aligned}
$$

$\mathrm{R}_{\mathrm{i}}$ denotes the return on the index of country $i$ whilst $\mathrm{R}_{\mathrm{r}}$ and $\mathrm{R}_{\mathrm{g}}$ denote the return on the regional benchmark index and the global benchmark index

\begin{tabular}{|c|c|c|c|c|c|c|c|c|c|c|c|c|c|c|c|}
\hline \multirow{2}{*}{ PERIOD } & \multicolumn{3}{|c|}{ BOTSWANA } & \multicolumn{3}{|c|}{ IVORY COAST } & \multicolumn{3}{|c|}{ EGYPY } & \multicolumn{3}{|c|}{ GHANA } & \multicolumn{3}{|c|}{ KENYA } \\
\hline & a & b & C & $\mathbf{a}$ & b & c & a & b & c & a & b & c & a & b & c \\
\hline 01/98 - 12/01 & 0.099 & .002 & 0.899 & 095 & 049 & 856 & .063 & 142 & 0.796 & 0.010 & 0.001 & 0.989 & 0.024 & 0.016 & .960 \\
\hline $01 / 99$ & 055 & 0.005 & 0.941 & 0.050 & 0.017 & 0.933 & .058 & 0.090 & 0.851 & 0.000 & 0.026 & .974 & 001 & .003 & 0.996 \\
\hline $01 / 00-$ & 170 & 0.020 & 0.810 & 0.097 & 0.009 & 0.894 & 0.095 & 0.156 & 0.749 & 0.026 & 0.004 & 0.971 & 0.072 & 0.025 & 0.903 \\
\hline $01 / 01-12 / 04$ & 0.162 & 0.000 & 0.837 & 0.063 & 0.009 & 0.928 & 0.034 & 0.182 & 0.783 & 0.006 & 0.032 & 0.962 & 0.008 & 0.037 & 0.955 \\
\hline $2 / 05$ & 116 & 0.025 & 0.859 & 0.024 & 0.003 & 0.972 & 0.003 & 0.027 & 0.970 & 0.014 & 0.044 & 0.942 & 0.000 & 0.013 & 0.986 \\
\hline & 011 & 0.025 & 0.964 & 0.035 & 0.027 & 0.9 & 0.096 & 0.0 & 0.8 & 0.007 & & & 0.005 & 0.021 & 0.974 \\
\hline 01/04 - & 001 & 0.062 & 0.938 & 0.021 & 0.018 & 0.961 & 0.153 & 0.003 & 0.845 & 0.080 & 0.018 & 0.902 & 0.082 & 0.018 & 0.900 \\
\hline \multirow{2}{*}{ PERIOD } & \multicolumn{3}{|c|}{ MAURITIUS } & \multicolumn{3}{|c|}{ MORROCO } & \multicolumn{3}{|c|}{ NIGERIA } & \multicolumn{3}{|c|}{ SOUTH AFRICA } & \multicolumn{3}{|c|}{ TUNISIA } \\
\hline & a & b & C & a & b & c & a & b & c & a & b & c & a & b & c \\
\hline & 0.000 & .015 & 985 & .009 & 00 & 0.98 & .06 & 0.01 & 0.924 & 0.661 & 0.291 & 0.048 & 0.018 & 0.004 & 0.978 \\
\hline$/ 02$ & 0.023 & 0.005 & 0.972 & 0.071 & 0.005 & 0.924 & 0.125 & 0.032 & 0.842 & 0.576 & 0.295 & 0.129 & 0.008 & 0.013 & 0.979 \\
\hline $01 / 00$ & 0.032 & 0.000 & 0.968 & 0.177 & 0.029 & 0.794 & 0.101 & 0.041 & 0.858 & 0.564 & 0.260 & 0.176 & 0.093 & 0.008 & 0.899 \\
\hline $01 / 01-12 / 04$ & 0.007 & 0.010 & 0.983 & 0.062 & 0.016 & 0.923 & 0.013 & 0.053 & 0.934 & 0.513 & 0.246 & 0.241 & 0.068 & 0.030 & 0.902 \\
\hline $01 / 02-12 / 05$ & 0.003 & 0.000 & 0.997 & 0.006 & 0.110 & 0.884 & 0.001 & 0.030 & 0.970 & 0.354 & 0.194 & 0.452 & 0.065 & 0.000 & 0.935 \\
\hline 01/03 - & 0.003 & 0.030 & 0.967 & 0.012 & 0.154 & 0.834 & 0.000 & 0.000 & 0.999 & 0.208 & 0.272 & 0.521 & 0.018 & 0.083 & 0.899 \\
\hline $01 / 04-12 / 07$ & 0.000 & 0.040 & 0.960 & 0.000 & 0.210 & 0.790 & 0.001 & 0.000 & 0.999 & 0.165 & 0.390 & 0.445 & 0.022 & 0.009 & 0.968 \\
\hline
\end{tabular}
respectively. The S\&P Global 1200 Index is used as a proxy for the global benchmark and S\&P/IFCG Middle East \& Africa Index is used as the regional benchmark. We use a fixed 4-year rolling window which is moved forward in 12-month intervals. In this case the first sub-period is January $1998-$

December 2001, the second covers the period January 1999 - December 2002 and so on yielding seven 4-year windows. All returns are calculated from the US dollar equivalents of the various indices and the full sample period is January 1998 to December 2007. 
Figure 1: Trend of Country Return Indices in Local Currency and Dollar

This figure shows the monthly index levels of the IFC country indices over the period January 1998 to December 2007 with January 1998 set to 100. Panel A presents the indices in local currency terms whilst Panel B presents the dollar equivalents.

\section{Panel A: Price Indices in Local Currency Terms}

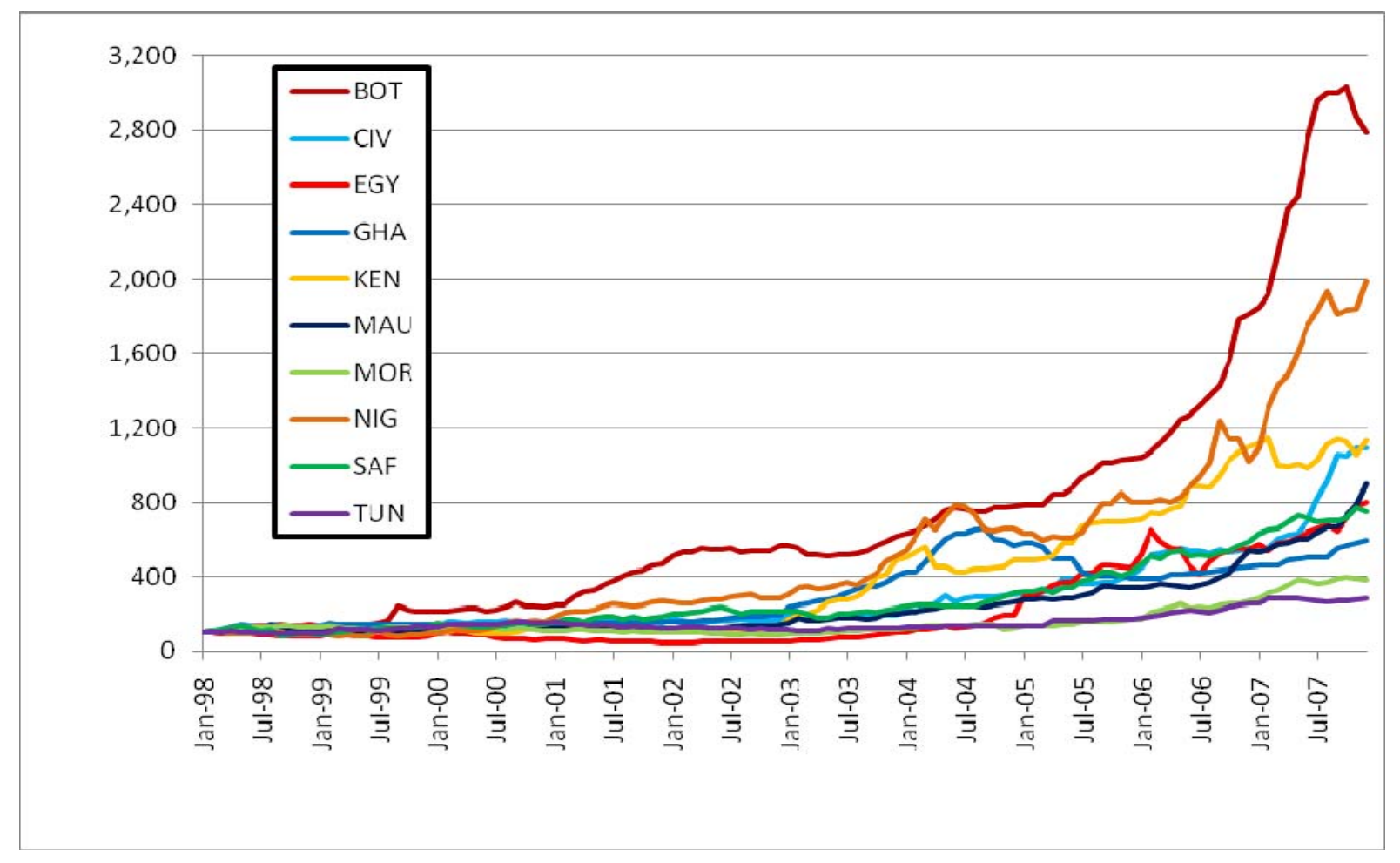

Panel B: Price Indices in Dollar Terms

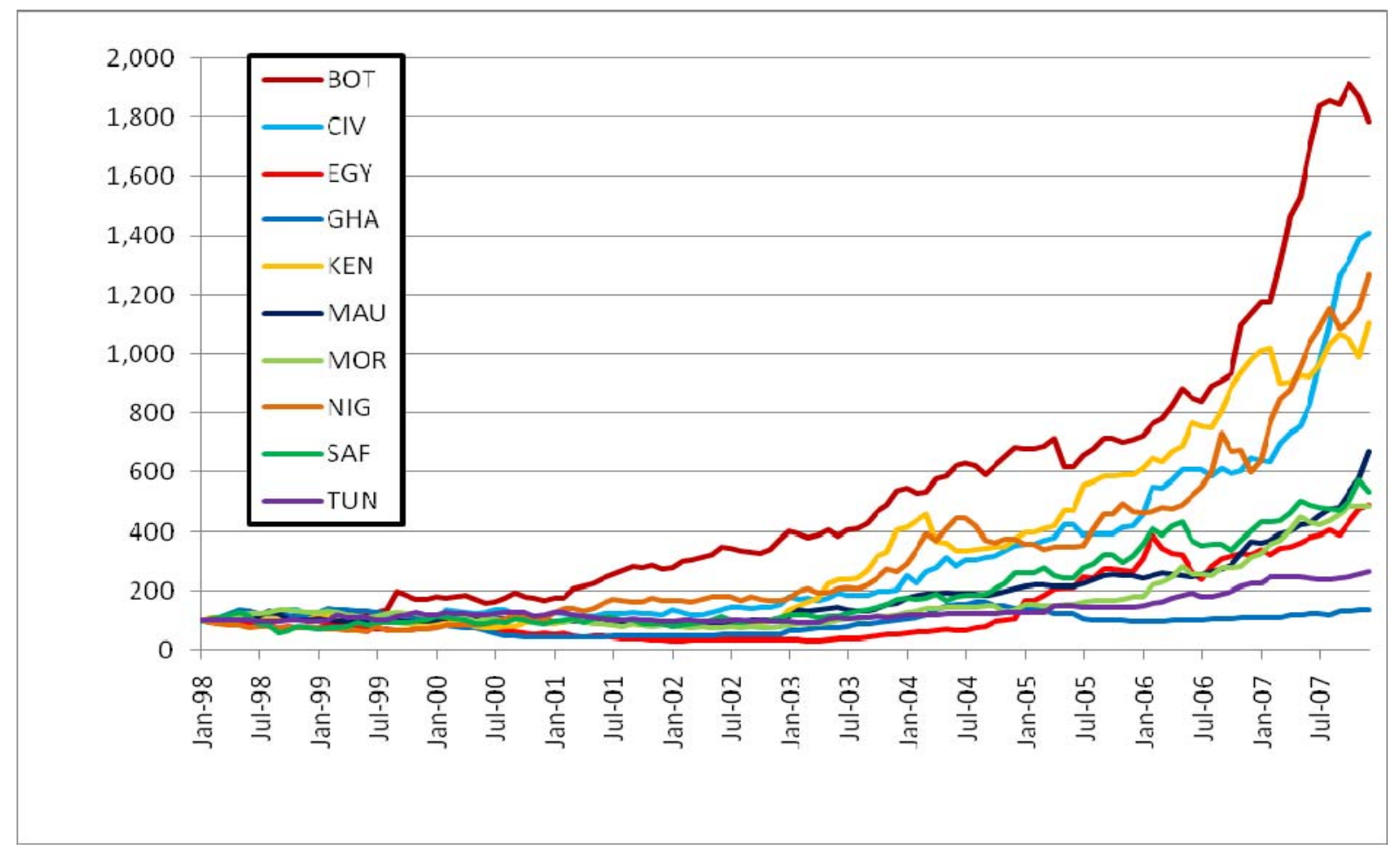


Figure 2: Trend of Regional and Global Integration Scores

Figure 2, illustrates the sum of the regional $\left(a_{i}\right)$ and global integration scores $\left(b_{i}\right)$ from the rolling window estimation. This illustrates the extent to which regional and global factors contribute to local stock market volatility. For each country $i$ we calculate:

where

$$
\begin{aligned}
& a_{\mathrm{i}}=\left(\beta_{\mathrm{ir}}\right)^{2} \operatorname{Var}\left(\mathrm{U}_{\mathrm{r}}\right) / \operatorname{Var}\left(\mathrm{R}_{\mathrm{i}}\right) \\
& \mathrm{b}_{\mathrm{i}}=\left(\beta_{\mathrm{ig}}\right)^{2} \operatorname{Var}\left(\mathrm{R}_{\mathrm{g}}\right) / \operatorname{Var}\left(\mathrm{R}_{\mathrm{i}}\right) \\
& \mathrm{c}_{\mathrm{i}}=\operatorname{Var}\left(\varepsilon_{\mathrm{i}}\right) / \operatorname{Var}\left(\mathrm{R}_{\mathrm{i}}\right)
\end{aligned}
$$

$$
\begin{aligned}
& \mathrm{R}_{\mathrm{i}}=\alpha_{\mathrm{i}}+\beta_{\mathrm{ir}} U_{\mathrm{r}}+\beta_{\mathrm{ig}} R_{\mathrm{g}}+\varepsilon_{\mathrm{i}} \\
& \mathrm{R}_{\mathrm{r}}=\lambda+\beta_{\mathrm{r}} R_{\mathrm{g}}+U_{\mathrm{r}}
\end{aligned}
$$

and $U_{\mathrm{r}}$, is obtained as the residual from the regression

$\mathrm{R}_{\mathrm{i}}$ denotes the return on the index of country $i$ whilst $\mathrm{R}_{\mathrm{r}}$ and $\mathrm{R}_{\mathrm{g}}$ denote the return on the regional benchmark index and the global benchmark index respectively. The S\&P Global 1200 Index is used as a proxy for the global benchmark and S\&P/IFCG Middle East \& Africa Index is used as the regional benchmark. We use a fixed 4-year rolling window which is moved forward in 12-month intervals. In this case the first sub-period is January 1998 - December 2001, the second covers the period January 1999 - December 2002 and so on yielding seven 4-year windows. All returns are calculated from the US dollar equivalents of the various indices and the full sample period is January 1998 to December 2007.

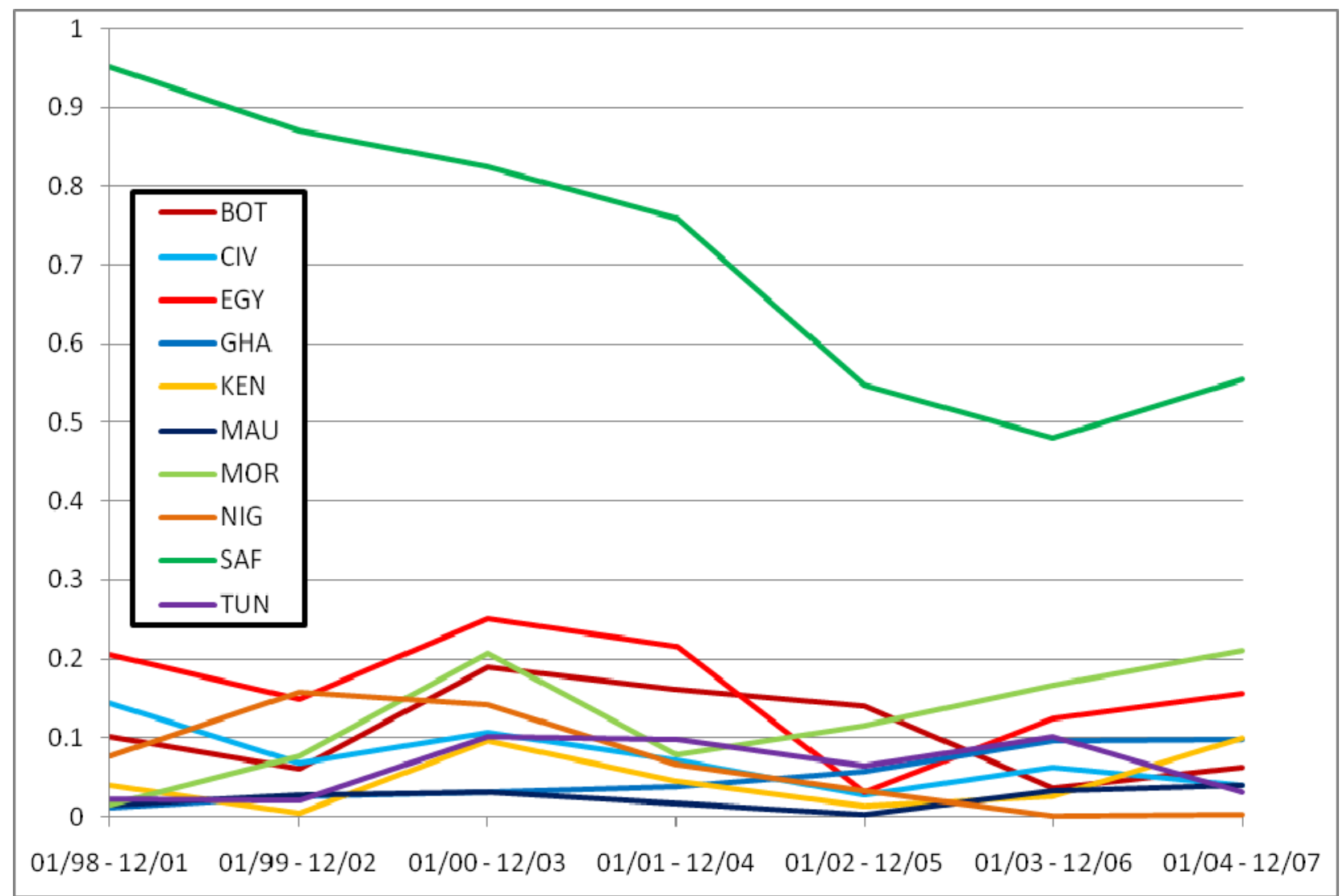

